\title{
A NONLINEAR BEHAVIOUR AND STRENGTH OF STEEL TOWERS OF LONG-SPAN SUSPENSION BRIDGES SUBJECT TO DEAD AND LIVE LOADS
}

\author{
By Taweep CHAISOMPHOB*, Akio HASEGAWA** and Fumio NISHINO***
}

\begin{abstract}
An ultimate strength analysis of the steel towers of the long-span suspension bridges is presented within the framework of an inelastic finite displacement theory of planar and spatial structures. The combined tower-cable system is employed to study the nonlinear effect of cables on the behaviour of huge towers. The Akashi-Kaikyo Bridge now under the first stage of construction for its seabed is selected in this study for investigations of ultimate strength behaviour of its steel towers subjected to the vertical dead and live loads. The current design practice of the Akashi towers is examined based on the present numerical results.

Keywords: suspension bridge, tower, cable, inelastic finite displacement, ultimate strength
\end{abstract}

\section{INTRODUCTION}

The recent developments of numerical computation techniques have made it possible to compute the response of long-span suspension bridges including geometrical and material nonlinearities. Regarding to the analyses of huge towers of suspension bridges in the plane of bridge axis, there seems to exist an ambiguity for the assumption of boundary conditions at the tower top. This may be due to very few number of theoretical and experimental investigations of the interaction between towers and cables of such long-span suspension bridges ${ }^{1), 2}$. In most cases, it is accepted in design analyses that the towers of hinged support at the top move only in the vertical direction ${ }^{1)}$.

This paper is to investigate an inelastic finite displacement behaviour of the huge towers of the steel suspension bridges. Since the Akashi-Kaikyo Bridge is the longest span suspension bridge ever planned, the present study is focused on the behaviour of the main towers of this particular bridge. The Akashi-Kaikyo Bridge connecting the Honshu and Awajishima Island located in the western part of Japan is one of the Honshu-Shikoku Bridge Projects and, at present, is under the first stage of construction for its seabed, and for its superstructure including the towers and cables under the stage of investigations for their design ${ }^{3}$. One of the plans under consideration is for the use of highways with a three-span suspension bridge with a center span of about 2000 meters and two side spans of about 950 meters each. Two main towers of the bridge will be the steel truss-stiffening-type frame structures, and the planned height is

* Dr. Eng., Ohbayashi Corporation Co. Ltd. (2-12-5, Uchikanda, Chiyoda-ku, Tokyo 113), formerly Graduate Student, Department of Civil Engineering, University of Tokyo.

** Member of JSCE, Dr. Eng., Associate Professor, Department of Civil Engineering, University of Tokyo (Bunkyo-ku Tokyo 113)

*** Member of JSCE, Ph. D., Professor, Department of Civil Engineering, University of Tokyo (Bunkyo-ku Tokyo 113). 


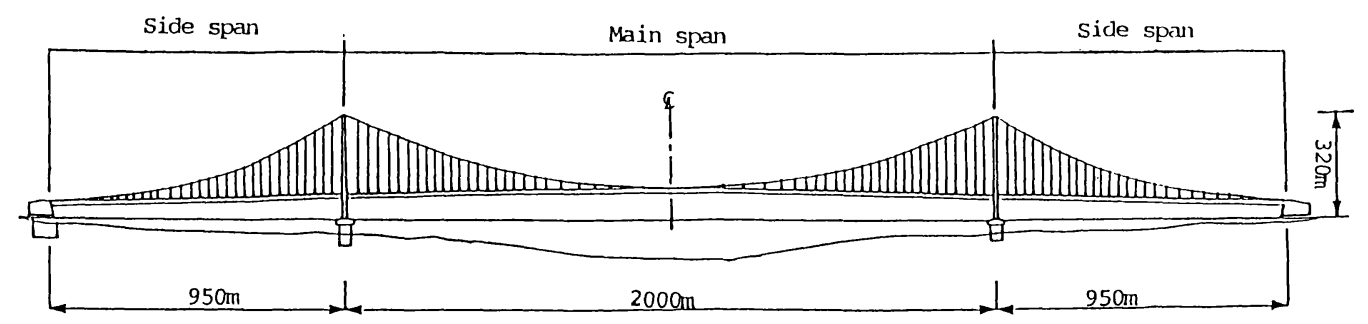

Fig. 1 General View of the Akashi-Kaikyo Bridge in Planning.

about 320 meters. Fig. 1 shows a general view of the Akashi-Kaikyo Bridge in planning.

In this study, the model of the so-called tower-cable system is proposed to account for the influences of cables on the tower bahaviour. By employing the updated Lagrangian formulation of beam and cable elements to account for the effects of finite displacement and also by adopting the so-called average stress-strain relation to account for the effects of inelasticities and residual stresses of welded steel members, the analytical procedures are established to obtain the nonlinear responses of the tower-cable system. The ultimate strength analyses of the towers of Akashi-Kaikyo Bridge subject to vertical dead and live loads are performed for the planar and spatial behaviour. The influences of the strain reversal and the variations of maximum residual compressive stresses on ultimate strength of this particular structure are examined. The comparison between the ultimate strength results of planar and spatial analyses of the huge towers is also discussed. Finally, from the results of the theoretical investigations, the ratio between the computed ultimate strength and the design loads of the Akashi towers is compared with the nominal safety factors specified by the current $\operatorname{codes}^{1)}$ in the case of dead and live loads only.

\section{ANALYTICAL PROCEDURES}

The analytical procedure to trace the load-displacement curve of the tower-cable system of suspension bridges developed in the present study can be divided into two subsequent steps as follows:

Step 1: To determine the initial cable configuration and its internal stress resultants at the self-equilibrium based on the classical cable theory ${ }^{4)}$.

Step 2: Once the first step is achieved, the subsequent load-displacement behaviour of discretized tower-cable system can be traced by the nonlinear finite element procedure with the use of beam and truss elements for towers and cables, respectively.

The proposed procedure avoids the very complicated treatment for cables involving the formulation of curved cable element or the method to find the cable profile at the self weight state. The error caused by discretizing cables into a series of truss elements can be reduced by employing an adequate number of truss elements.

\section{(1) Separate cable analysis}

Consider the suspended cable structure of the three-span suspension bridge under the application of the vertical uniformly distributed dead and live loads of cables and stiffening girders in Fig. 2. It is noted that the loading pattern of live loads on all spans is selected as the most severe loading condition for the towers ${ }^{1)}$ which is of primary concern in this study. In practice, the cable profile of suspension bridges is designed to be flat, i. e., the ratio of sag-to-span is $1: 8$ or less.

The parabolic cable theory can be, therefore, adopted without introducing an unacceptable error ${ }^{4)}$. By utilizing this parabolic approximation, the profile and the stress resultants of suspended cables in Fig. 2 can be determined by specifying values of the characteristic length such as sag of main and side

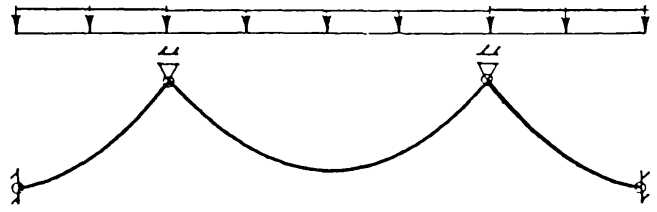

Fig. 2 Suspended Cable of Suspension Bridge. 
spans $^{5)}$.

\section{( 2 ) Subsequent nonlinear analysis of discretized tower-cable system}

In order to take into account the geometrical and material nonlinearities, the updated Lagrangian procedure together with the method of average stress-strain relation is utilized to formulate the nonlinear beam and truss elements modelling the discretized tower-cable system (see Fig. 6 and 7 for planar and spatial analyses, respectively). The load-displacement responses of the structures are obtained by performing the Newton-Raphson iteration of the incremental stiffness equations with the aid of load and displacement controls ${ }^{5}$.

The Akashi tower cross-section, which is of concern of this study, is a complicated multi-box girder shape (see Fig. 4). Hence, compared with Saint-Venant torsion, the warping torsion is much smaller and its effect is neglected in the spatial analysis. In view of the updated Lagrangian formulation, substituting the appropriate kinematic fields and interpolation functions for non-warping thin-walled beams without the effect of shear deformation ${ }^{6}$ into the linearized virtual work equation ${ }^{7)}$ yields the following incremental stiffness equations of a prismatic straight beam element as

$[K]\{u\}=\{F\}-\{P\}$

where $[K]$ is the tangential stiffness matrix ; $\{u\}$ and $\{F\}$ are the vectors of nodal incremental displacement and external forces, respectively; $\{P\}$ is the vector of nodal point forces equivalent to the element stresses $^{5}$. For the incremental stiffness equations of a spatial truss element, the same form as Eq. (1 ${ }^{5)}$ can be obtained by adopting the assumptions of trusses ${ }^{6}$. It is emphasized that modifications are required to truss elements so that they will behave as cable elements, i. e., they become ineffective in compression.

In order to form $[K]$ and $\{P\}$ for the beam elements adopted to model welded steel tower members, the numerical integration inside the volume of each element is required, in which it can be divided into the integration along the beam axis and across the cross-section. In the present study, the Gauss numerical integration is utilized to perform the integration along the beam axis. The integration across the cross-section concerning effects of inelasticities and residual stresses can be performed through the adoption of the method of average stress-strain relation as illustrated in Fig. 3. For the steel materials with residual stresses, the point 1 and 2 in Fig. 3 are defined by specifying the yield stress $\sigma_{y}$ and the magnitude of maximum residual compressive stress $\sigma_{r c}$ with the use of the magnitude of residual tensile stress set to be $\sigma_{y}^{8 / .9)}$. In addition, the curve in the range of partial yielding (between point 1 and 2 in Fig. 3) can be approximated by the third order polynomial function ${ }^{8}$. Since this method is applicable only for the problem of uniform stresses ${ }^{8}$, it can be employed in the beam problem by dividing the cross-section into a sufficient number of small portions so that the stress distribution can be regarded as an uniform distribution inside each of those portions ${ }^{5}$. It is worth noting that the method of average stress-strain relation proposed here is easy to handle for a complicated beam cross-section such as Akashi tower section (see Fig. 4). The proposed method is also appropriate to treat the residual stress distribution which are inherently subject to variations as observed in experimental results.

For the process of assembling element stiffness equations into the global stiffness equations, the coordinate transformation and the updating of coordinates which have been developed in Ref. 6) are employed in this study.

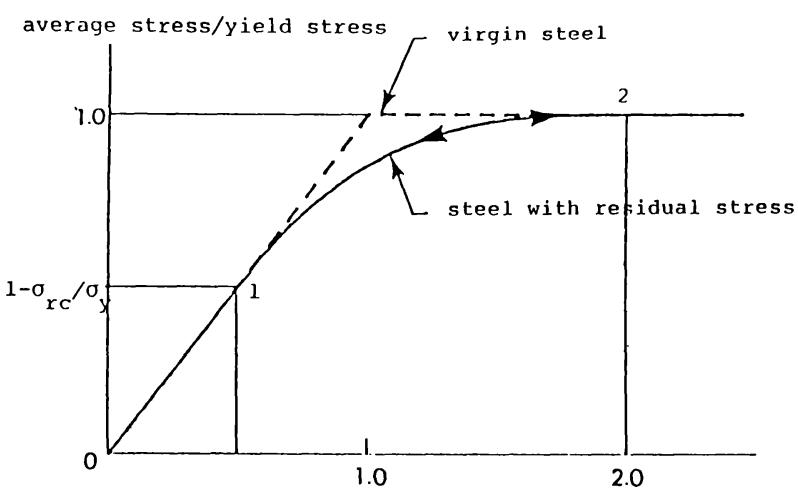

average strain/yield strain

Fig. 3 Average Stress-Strain Relation. 


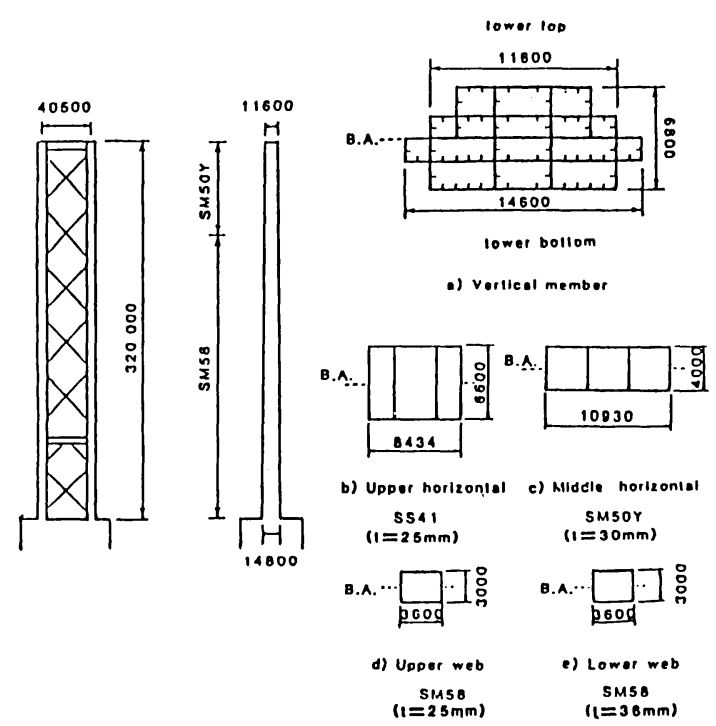

Fig. 4 Geometry of Main Tower of the Akashi-Kaikyo Bridge.

\section{ANALYTICAL MODELS AND LOAD- ING CONDITIONS}

From the preliminary designs for the AkashiKaikyo Bridge examined in the past ${ }^{10)}$, the geometry and cross-sectional dimensions of the main tower are given in Fig. 4. The material properties used for the steel towers are : SS 41 (yield stress $\left.\sigma_{y}=2.4 \times 10^{4} \mathrm{t} / \mathrm{m}^{2}\right)$, SM $50 \mathrm{Y}\left(\sigma_{y}=3.6 \times 10^{4} \mathrm{t} / \mathrm{m}^{2}\right)$, SM 58 $\left(\sigma_{y}=4.6 \times 10^{4} \mathrm{t} / \mathrm{m}^{2}\right)$ and the Young's Modulus $=2.1 \times 10^{7} \mathrm{t} / \mathrm{m}^{2}(\mathrm{t}: \mathrm{ton}, \mathrm{m}: \text { metre })^{9)}$. For the steel cables, the double-cables of PWS (Parallel Wire Strand), 127 (wires/1 strand) $\times 169$ (strands/1 cable), are employed for each side of the bridge. The diameter of a wire $=5.20 \mathrm{~mm}$ and the cross-sectional area of a cable $=0.45581 \mathrm{~m}^{2}$. The material properties of steel wire are as follows : rupture stress $\sigma_{u}=19.2 \times$ $10^{4} \mathrm{t} / \mathrm{m}^{2}$ and the Young's Modulus $=2 \times 10^{7} \mathrm{t} / \mathrm{m}^{29)}$. It is noted that the values of allowable stresses are obtained from the yield stresses divided by the nominal safety factors 1.7 for towers and 3. 0 for cables as adopted in the current codes $^{9}$. In addition, the values of the cable sag of the main and side spans are $233 \mathrm{~m}$ and $51.7 \mathrm{~m}$, respectively.

\section{(1) Basic assumptions}

For the simplicity of analyses without losing any generality, the following assumptions are introduced as:

a) The material modelled by the average stress-strain relation as shown in Fig. 3 is adopted for the towers and the linear elastic material adopted for the cables. The latter is confirmed by the fact that, even with the use of actual nonlinear stress-strain relation for the cables, the computational results for the load-displacement relation of the structure have not differed as much from the results with the linear elastic material (See Ref.5) by the reason that the arising stresses in cables are well below the rupture stresses within the range of the present computation.

b) The effects of local buckling of stiffened plate components are not taken into consideration, since there exists no possibility of this phenomena because of the relatively smaller width-thickness ratio of the plate and the stiffener arrangements.

c) All the tower members are connected by welding and hence are assumed to be connected by rigid 
joints. For the joint at the tower top on which the cable is placed, a hinged connection, i. e., continuity of all three components of the translation but discontinuity of those of the rotation, is assumed due to the fact that the vertical dead loads of long-span suspension bridges are considerably large so that no relative movement between towers and cables may occur.

d) The effects of stiffeners on the torsion of the tower cross-section are neglected, but those on the axial and bending rigidity are included.

\section{(2) Analytical models}

The Akashi tower in Fig. 4 is modelled by the assemblage of prismatic straight beam elements as illustrated in Fig. 5 which includes the node numbers representing not only the points of tower joints but also those of separating the parts of different plate thickness, rib section and material property. For the cables modelled by truss elements, it is found numerically that by dividing the side span cable into ten truss elements and the half of the main span cable into ten truss elements, the error due to the discretization reduces to an acceptable level.

The models for planar analyses can be divided into two different types of the structures, i. e. , the frame structure in the plane of perpendicular-to-bridge axis as shown in Fig. 5 called the planar tower model and the combined tower-cable structure in the plane of bridge axis as shown in Fig. 6 called the planar tower-cable model. In the case of the planar tower-cable model, the effect of bracing members of the tower is not taken into account due to the negligible contributions from their flexural stiffness to the planar behaviour of towers ${ }^{1 / 2)}$. Fig. 7 shows the spatial tower-cable model consisting of spatial thin-walled beam and truss elements. For the spatial tower-cable model, only St. Venant's shear stress is reflected on the evaluation of the tangent modulus by the method described in Ref. 6). However, it is noted for simplicity that bending shear is not considered on this purpose both for the planar and spatial models.

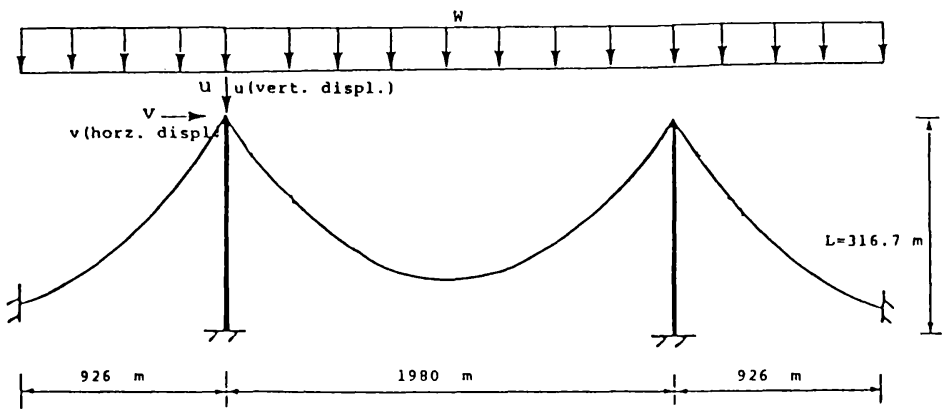

Fig. 6 Planar Tower-Cable Model.

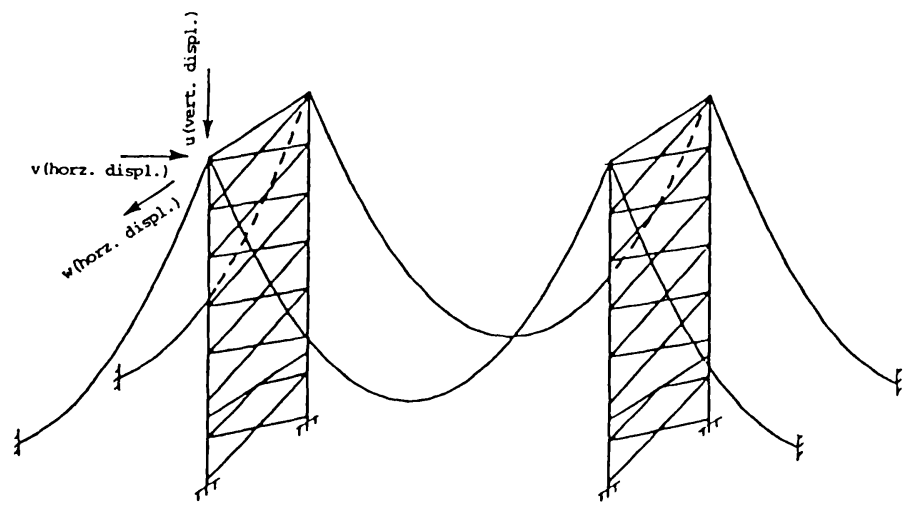

Fig. 7 Spatial Tower-Cable Model. 
Table 1 Dead Loads (unit: ton).

\begin{tabular}{rcccr}
\hline Node & $\begin{array}{c}\text { Vertica1 } \\
\text { member }\end{array}$ & $\begin{array}{c}\text { Bracing } \\
\text { member }\end{array}$ & Addition* & Total \\
\hline 14.15 & 137 & 178 & 340 & 655 \\
13.16 & 751 & 32 & - & 783 \\
12.17 & 1466 & 64 & - & 1530 \\
10.19 & 1495 & 64 & - & 1559 \\
9.20 & 1524 & 64 & - & 1588 \\
7.22 & 1692 & 64 & - & 1756 \\
6.23 & 1163 & 32 & - & 1195 \\
5.24 & 794 & 97 & 512 & 1403 \\
4.25 & 1205 & 100 & - & 1305 \\
2.27 & 907 & 50 & - & 957 \\
1.28 & 102 & - & 178 & 280 \\
$29-33$ & - & 128 & - & 128 \\
34 & - & 294 & 760 & 1054 \\
35 & - & 200 & - & 200 \\
\hline Note: & $=$ reaction forces from sadd1es \\
& and rings. & &
\end{tabular}

dead load, $w / w_{d}$

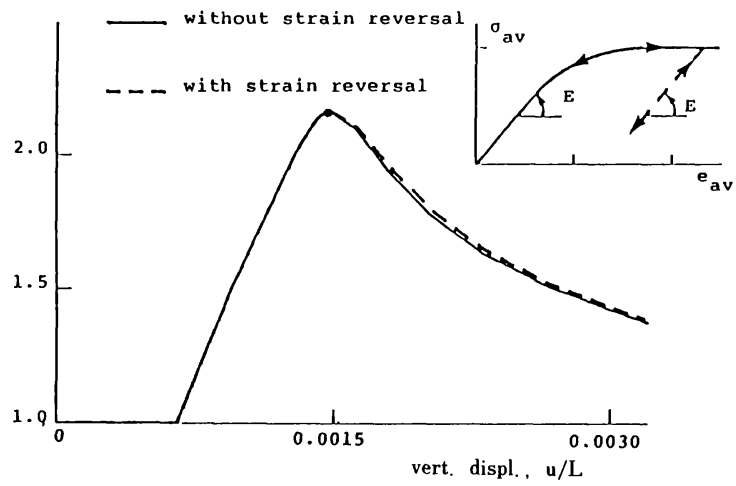

Fig. 8 Comparison between Results with and without Strain Reversal

\section{(3) Loading conditions}

The dead and live loads of the structures can be divided into two groups, i. e., the dead loads of towers and the dead and live loads of suspended structures. The former is considered to be the concentrated loads acting at each node of tower members. Their values at the corresponding node numbers shown in Fig. 5 are given by Table $1^{10)}$. The latter consists the dead loads of cables, hangers and stiffening girders and the vehicle loads on stiffening girders. They are treated as the uniformly distributed loads per unit horizontal length of cables denoted by $W$ in Fig. 6 and used for the analyses of the planar and spatial tower-cable models. It is noted that, because of sufficient flexibility of hangers, the stiffening girder is treated simply as dead load for the tower-cable system, and therefore the interaction between the stiffening girder and the tower-cable system is not considered at present analysis. The reaction of these loads exerted on the tower top is represented by $P$, and used for the analysis of the planar tower model as can be seen in Fig. 5 . According to Ref. 10), the design values of $W$ are $22.15 \mathrm{t} / \mathrm{m}$ for the main span and $22.475 \mathrm{t} / \mathrm{m}$ for the side span, respectively, and that of $P$ is $50344 \mathrm{t}$. For the purpose of explanation, these design dead and live loads are indicated by $W_{d}$ for the planar and spatial tower-cable models, and by $P_{d}$ for the planar tower model, respectively. As discussed earlier, the full-span loading pattern of live loads gives the state of maximum reaction $P$ at the tower top ${ }^{1)}$.

\section{LOAD-DISPLACEMENT BEHAVIOUR}

Due to a symmetry of structures and loading conditions, a half of planar and spatial tower-cable models are analysed. By varying all of vertical dead and live loads of the structures, the load-displacement curves are traced up to the ultimate states which are defined by the maximum point of the curves. For the expression of load-displacement curves, the ratio between vertical loads $(P$ or $W)$ and design loads $\left(P_{d}\right.$ or $\left.W_{d}\right)$ is plotted against that of the displacement at the tower top $(u, v, w)$ and the tower height $(L)$. The directions of displacement follow those appeared in Fig. 5-7. An ultimate point is represented by a dot on load-displacement curves. It should be noted that according to the procedures described in Chapter 2, a starting point of the load-displacement curves of the planar and spatial tower-cable models is chosen to be the state of design dead and live loads, i. e., $W / W_{d}=1$.

\section{(1) Verification of no strain reversal assumption}

It is recognized that in practice no strain reversal is an assumption usually adopted in the ultimate strength analysis of steel structures. From the theoretical point of view, this assumption is equivalent to nonlinear elastic constitutive relation. In reality, some parts of structures undergoing the unloading path always exist in the vicinity of ultimate state and beyond this state. In order to show this influence on the 
behaviour of huge towers, the analyses of the planar tower-cable model with the value of $\sigma_{r c}$ set to be $0.5 \sigma_{y}$ are performed based on the assumptions without and with strain reversal and the results are shown in Fig. 8. It can be seen that beyond the ultimate state two curves start to deviate from each other, but a difference is very small, i. e. , $\leqq 2 \%$, due to the effect of the strain reversal of small magnitude occurring very locally inside tower cross-sections near the ultimate state. Even at the extended unloading stage, the difference is not remarkable. This may come from that such a complex assemblage of the structure may cause some cancelling effects on the behaviour, which is somewhat different feature from the behaviour of independent member components. From these results, a simple nonlinear elastic stress-strain relationship might be practically adopted for an analysis of these particular towers without losing an acceptable accuracy.

\section{(2) Influences of variations of maximum residual compressive stresses}

By changing the values of $\sigma_{r c}$ to be $0,0.3 \sigma_{y}, 0.4 \sigma_{y}$ and $0.5 \sigma_{y}$, the load-displacement curves of the planar tower-cable model are obtained, respectively, and shown in Fig. 9. The noticeable reduction of ultimate strength can be observed especially in the case of $\sigma_{r c}=0.5 \sigma_{y}$ compared with the case of no residual stress, but the differences among the cases of $\sigma_{r c}=(0.3-0.5) \sigma_{y}$ are less than $5 \%$. Hence, from the viewpoint of practical design of huge towers, the adoption of the values of maximum residual compressive stresses ranging from $0.3 \sigma_{y}$ to $0.5 \sigma_{y}$ may not cause a serious consequence. Nevertheless, to be conservative, the constitutive model with $\sigma_{r c}=0.5 \sigma_{y}$ is employed throughout this analysis.

\section{(3) Results of planar and spatial analyses}

The load-displacement curves are plotted in Fig. 10, 11 and 12 in the cases of the planar tower model, the planar tower-cable model and the spatial tower-cable model, respectively. In the case of the tower-cable models, a decrease of the horizontal displacement after reaching the ultimate state, as can be observed by solid lines in Fig. 11 or 12, indicates the interaction between towers and cables. For the comparison of the ultimate loads for the planar and spatial analyses, the values of ultimate loads are about 1.85, 2.17 and 2. 04 for the planar tower model, the planar tower-cable model and the spatial tower-cable model, respectively. It can be seen that the ultimate loads of two models with cables are larger than that of the planar tower model. The reason for this tendency is that the cable effects seem to improve the performance of the tower behaviour. Moreover, as can be expected naturally, the ultimate strength of the spatial tower-cable model falls in between those of two planar models.

\section{(4) Discussions}

As mentioned earlier, the nominal value of the factor of safety is specified to be 1.7 in current design practice of huge towers ${ }^{1) .9)}$ when only the principal loads, i. e., the dead and live loads are considered.

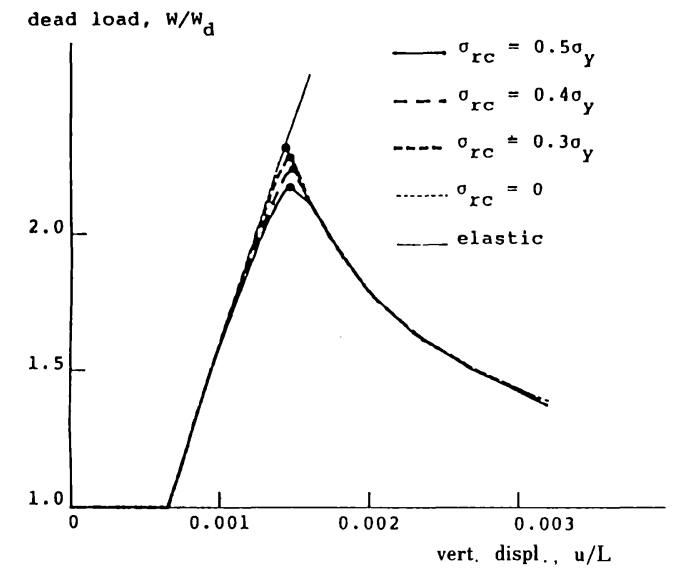

Fig. 9 Comparison among Results with Different Values of $\sigma_{\tau c}$.

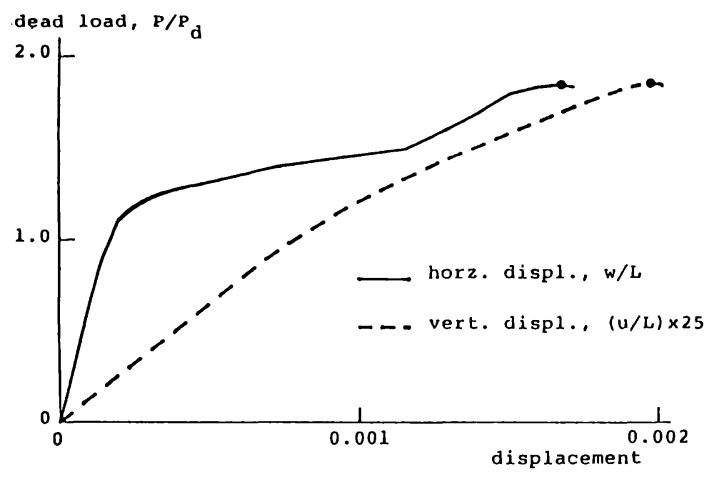

Fig. 10 Results for Planar Tower Model. 


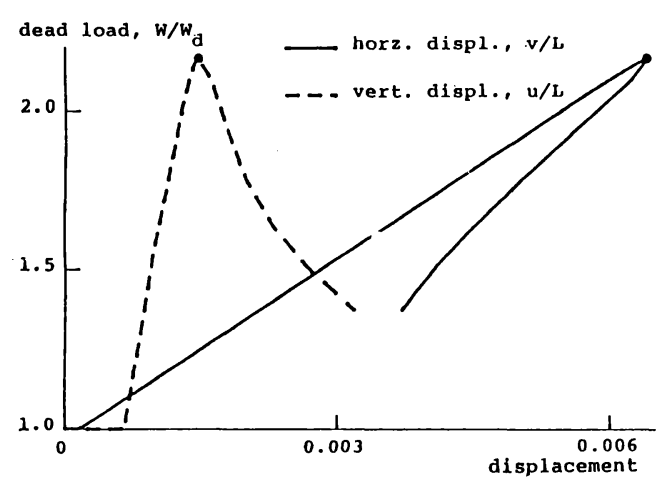

Fig. 11 Results for Planar Tower-Cable Model.

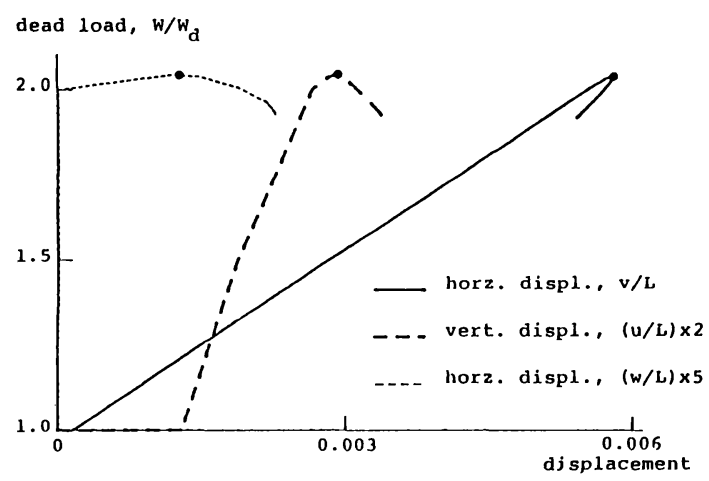

Fig. 12 Results for Spatial Tower-Cable Model.

Since the values of ultimate loads theoretically obtained in this study are nondimensionalized with their design loads specified in current $\operatorname{codes}^{1 / .10)}$, it is informative to compare these values with the nominal safety factors of 1.7. It is obvious that the computed ultimate loads for the spatial analysis is about 2.04 which is greater than 1.7. This might be because of the difference due to models and analytical procedures, in which the present results obtained by performing the inelastic finite displacement analysis of the spatial tower-cable model seem to be more realistic than those obtained by the current design procedures involving the separate planar analyses of the towers neglecting effects of cables. This difference can also be confirmed by comparing the obtained ultimate loads based on the spatial analyses with those based on the planar analyses as discussed in previous section. Therefore, in the design of huge towers of suspension bridges, more elaborate design procedures, such as the analytical procedures for the spatial tower-cable model proposed in the present study, are preferred, and these accurate procedures might lead to an economic design of the huge towers.

\section{CONCLUDING REMARKS}

The following conclusions have been drawn from this study.

(1) Without introducing any artificial boundary conditions at the top of towers, the proposed tower-cable system can automatically account for the highly nonlinear effects of cables on the tower behaviour, and hence this tower-cable model can be utilized as an effective tool for the investigations of ultimate strength behaviour of the main towers of long-span suspension bridges.

(2) The analytical procedures including the separate cable analysis to determine the cable configuration and its internal stress resultants at the self equilibrium and the subsequent nonlinear analysis of discretized structures are established to obtain the nonlinear responses of the tower-cable system of long-span suspension bridges with the use of truss elements for cables. This proposed procedures can also be extended to the nonlinear analyses of other types of cable-supported structures such as cable-stayed bridges, guyed towers ${ }^{11)}$, etc.

(3) Based on the results of ultimate strength analyses of the main towers of the Akashi-Kaikyo Bridge subjected to only dead and live loads acting on the bridge, the Akashi towers can resist up to the magnitude about twice the design dead and live loads which is larger than the nominal factor of safety of 1.7 specified in current codes.

(4) As can be observed from the comparison between the results of spatial and planar analyses, there exists some difference in the obtained ultimate strength. Hence, in the design of huge structures, such as the towers of Akashi-Kaikyo Bridge, more elaborate design procedures incorporating the spatial behaviour of the tower-cable system are preferred for accurate and economic design.

Because of the page limitation, the paper has dealt with the static inelastic finite displacement analysis 
only for the case of vertical dead and live loads. For the design of the towers of long-span suspension bridges, however, the effects of horizontal loadings such as wind and earthquake loads appear to be also important. Although the behavior against those horizontal loadings including the dynamic behaviour has been considered out of scope at the present study, it will possibly be presented for future publications (See Ref. 5)).

\section{ACKNOWLEDGEMENTS}

This paper is based on the doctoral dissertation thesis of the first author at the University of Tokyo, who was awarded the scholarship by the Japanese Government. The work is also supported by the research grant through the Honshu-Shikoku Bridge Authority. The authors are indepted to Dr. H. Horii of the University of Tokyo for his valuable suggestions.

\section{REFERENCES}

1) Honshu-Shikoku Bridge Authority: Guideline for the Design of Main Towers, 1980 (in Japanese).

2) Birdsal, B. : The Suspension Bridge Tower Cantilever Problem, Proc. ASCE, April 1942.

3) Honshu-Shikoku Bridge Authority : Outline of Honshu-Shikoku Bridge Project, 1983.

4) Gimsing, N. J. : Cable Supported Bridges Concept and Design, John Wiley Sons, 1983.

5) Chaisomphob, T. : The Inelastic Finite Displacement Behaviour of Steel Towers of Long-Span Suspension Bridges, Thesis presented to Univ. of Tokyo, in 1987, in partial fulfillment of the requirements for the degree of Doctor of Engineering.

6) Hasegawa, A., Liyanage, K. K. and Nishino, F. : Spatial Instability and Nonlinear Finite Displacement Analysis of Thin-Walled Members and Frames, J. of the Faculty of Engng, Univ. of Tokyo (B), Vol. 38, No. 4, 1986.

7) Washizu, K. : Variational Methods in Elasticity and Plasticity, Pergamon Press, London, 1982.

8) Okamura, T., Hasegawa, A., Nishino, F. and Nagahama, M. : Inelastic Buckling Analysis of Stiffened Plates by Finite Difference Method, Proc. of Annual Conf. JSCE, 1972 (in Japanese).

9) Honshu-Shikoku Bridge Authority: Standard for the Disign of Superstructures, 1980 (in Japanese).

10) Honshu-Shikoku Bridge Authority : A Preliminary Design of the Akashi-Kaikyo Bridge, Unpublished document (in Japanese) .

11) Shrestha, P., Hasegawa, A. and Chaisomphob, T. : An Elastic Finite Displacement Analysis of Cable Supported Structures, Proc. of International Conf. on Cable-Stayed Bridges, Bangkok, Thailand, pp. 209-223 November 1987.

(Received December 2 1987) 